\title{
RETRIEVAL OF DUST MICROPHYSICAL PROPERTIES
}

\author{
Böckmann, Christine ${ }^{1, *}$, Samaras, Stefanos ${ }^{2}$ and Haarig, Moritz ${ }^{3}$ \\ ${ }^{I}$ University of Potsdam, Institute of Mathematics, Potsdam, Germany, \\ ${ }^{2}$ German Aerospace Center, Oberpfaffenhofen, Germany, \\ ${ }^{3}$ Leibnitz Institute of Tropospheric Research, TROPOS, Leipzig, Germany \\ *bockmann@uni-potsdam.de
}

\begin{abstract}
An intense mineral dust event from the Saharan desert was observed over the Island of Barbados after a long-range transport over the Atlantic Ocean during SALTRACE Campaign in June 2014. We analyze data from a multi-wavelength Raman-lidar system of Leibniz Institute for Tropospheric Research (TROPOS) called BERTHA (Backscatter Extinction lidar Ratio Temperature Humidity profiling Apparatus) to derive the aerosol microphysical properties of the inspected layer via regularization using the software SphInX (Spheroidal Inversion eXperiments). These parameters were found to be within credible ranges.
\end{abstract}

\section{INTRODUCTION}

The data was obtained from the multi-wavelength Raman-lidar system of TROPOS located at the ground-based remote sensing station in Husbands, north of the capital Bridgetown at the west coast of Barbados $\left(13.15^{\circ} \mathrm{N}, 59.62^{\circ} \mathrm{W}\right.$, and $110 \mathrm{~m}$ above sea level) on 20 June 2014. The BERTHA system is a container-based, multi-wavelength polarization Raman lidar. It is able to take measurements of the depolarization ratio at three wavelengths $(355,532$ and $1064 \mathrm{~nm}$ ) simultaneously, which is crucial to characterize the dust after long-range transport, see $[1,2,3]$ for more details. It operates as a $3+2+3$ lidar system (3 backscatter coefficients $\beta$, 2 extinction coefficients $\alpha$ and 3 depolarization ratios). The signals are detected with a range resolution of $7.5 \mathrm{~m}$ and a time resolution of $10 \mathrm{~s}$. Additionally, an AErosol RObotic NETwork (AERONET) sun photometer was operated at the field site. The layers of interest can be seen in Fig. 1. Here we selected an altitude range from $1.5(2.0)-2.75 \mathrm{~km}$ and $3.25-4 \mathrm{~km}$ for the microphysical inversion. The optical profiles are shown in Fig. 2.

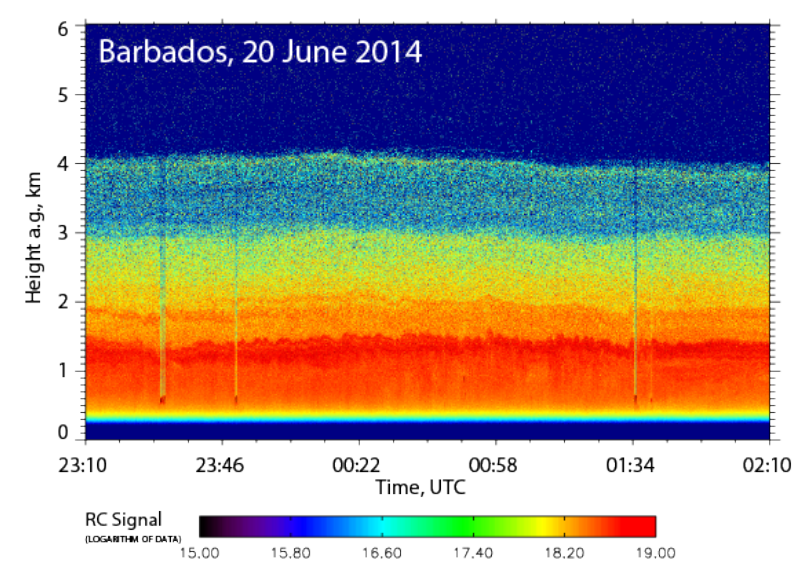

Figure 1. Lidar range-corrected signal at $1064 \mathrm{~nm}$.

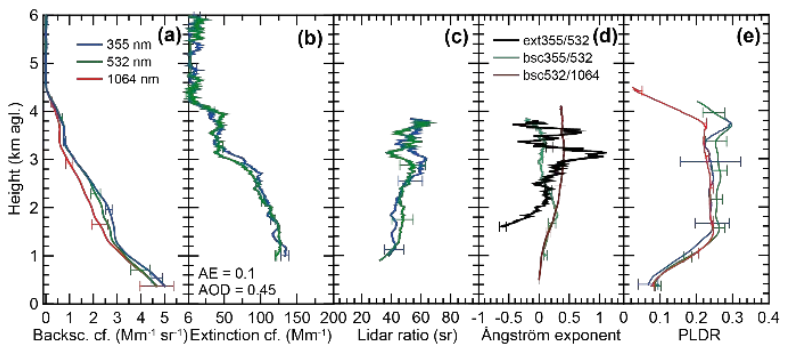

Figure 2. Optical properties captured by BERTHA (20 June 2014 23:10-02:10 UTC, $750 \mathrm{~m}$ smoothed). PLDR-particle linear depolarization ratio.

\section{METHODOLOGY}

We consider a spheroid-particle approximation, which needs only one additional parameter, i.e. the aspect ratio $a$, to be fully defined. The model relating the optical parameters $\mathcal{L}(\lambda)$ with the volume size distribution $v(r, a)$ is described by the action of a 2D Fredholm integral operator of the $1^{\text {st }}$ kind

$$
\begin{aligned}
\mathcal{L}(\lambda)= & \int_{a_{\min }}^{a_{\max }} \int_{r_{\min }}^{r_{\max }} \\
& \frac{3 A}{16 \pi r^{3}} Q_{\alpha / \beta}(r, \lambda, a ; m) v(r, a) \mathrm{d} r d a,
\end{aligned}
$$


where $A$ is the particle surface area, $m$ is the complex refractive index (RI), $\lambda$ is the wavelength, $r$ is the volume equivalent radius, $\left[r_{\text {min }}, r_{\text {max }}\right]$ and $\left[a_{\min }, a_{\max }\right]$ are sensible radius and aspect ratio ranges. $\mathcal{L}(\lambda)$ denotes either the 2 extinction or 6 backscatter (cross and parallel) coefficients, and $Q$ stands for either the extinction or the backscatter (dimensionless) efficiencies, respectively. Identifying $\mathcal{L}(\lambda)$ as our measurement data and $v(r, a)$ as the unknown volume distribution, the problem reduces to the inversion of Eq. (1). Knowing the volume distribution, we can then extract the following microphysical parameters

- Total surface-area concentration $\left(\mu \mathrm{m}^{2} \mathrm{~cm}^{-3}\right)$

$s_{\mathrm{t}}=\int_{a_{\min }}^{a_{\max }} \int_{r_{\min }}^{r_{\max }} \frac{3}{\pi r^{3}} G(r, a) v(r, a) d r d a$

- Total volume concentration $\left(\mu \mathrm{m}^{3} \mathrm{~cm}^{-3}\right)$

$v_{\mathrm{t}}=\int_{a_{\min }}^{a_{\max }} \int_{r_{\min }}^{r_{\max }} v(r, a) d r d a$,

- Effective radius $(\mu \mathrm{m}) \quad r_{\text {eff }}=3 \frac{v_{t}}{s_{t}}$.

The function $G(r, a)$ denotes here the spheroidal geometrical cross section. In addition, the complex RI and the single scattering albedo (SSA) in $355 \mathrm{~nm}$ and $532 \mathrm{~nm}$ are retrieved. Note, that in this work the common assumption of wavelengthindependent RI is made, as an element of the predefined grid introduced.

A precalculated data-base will be used, created by the software tool Mieschka [4] which is able to perform scattering-related T-matrix calculations for spherical particles and rotationally symmetric non-spherical particles. Mieschka's look-up tables include scattering efficiencies for a $6 \times 7(\mathfrak{R}(\mathrm{m}) \times$ $\mathfrak{I}(m)$ ) refractive index grid (a total of 42 RI values), 7 different aspect ratios and a size parameter range $[0.02,40 \mu \mathrm{m}]$ with a resolution of $0.2 \mu \mathrm{m}$. While the maximum size parameter is reasonably large for other applications, its potential cannot be fully exploited here in terms of the radius extent, since the lidar wavelengths restricts the maximum radius $\left(r_{\max }\right)$ to appr. $2.2 \mu \mathrm{m}$. The resolution gap in the aspect ratio needed for the integrations is handled by interpolation to the nearest neighbor. Solving Eq. (1) requires discretization, regularization and a parameter choice rule handled by the software SphInX, see e.g. $[5,6,7]$.

\section{RESULTS}

A reasonable layer selection where both lidar ratio and the Ångström exponent are relatively constant,

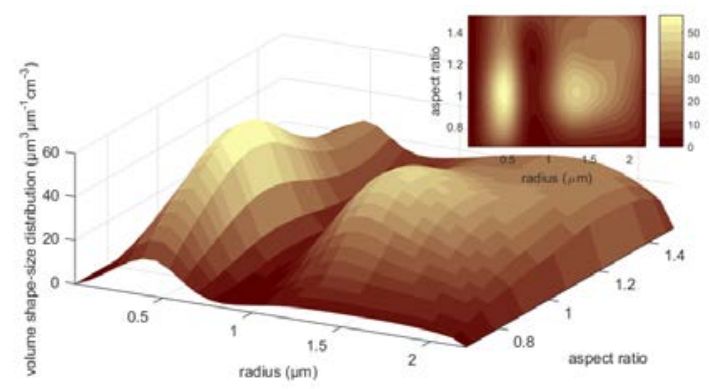

Figure 3. Retrieved shape-size distribution shown in $3 \mathrm{D}$ and in ar-plane for $1.5-2.75 \mathrm{~km}$.
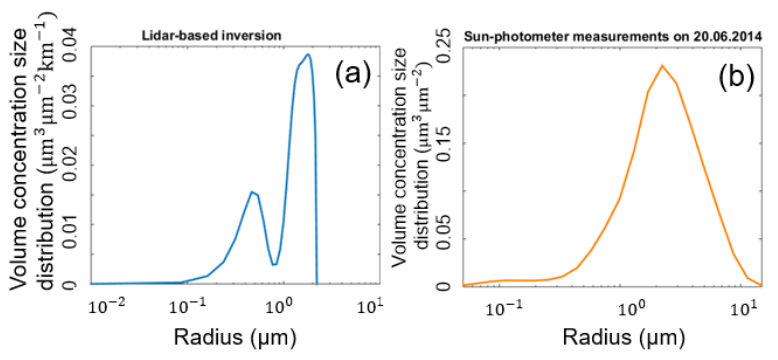

Figure 4. Retrieved lidar-reduced VCSD for 1.5$2.75 \mathrm{~km}$ (left) and AERONET VCSD (right).

the aerosol properties are more representative of the total behavior and where the optical profiles $(\alpha$ and $\beta$ ) are still intense is the one in $2-2.75 \mathrm{~km}$, see Table 1. For the inversion we used 100 iterations of Padé regularization [6, 7], 9-14 spline points and spline degree within the range $2-5$. The refractive index grid (RIG) was defined in the broad form of $\mathrm{RRI} \times \mathrm{IRI}=[1.4,1.5,1.6,1.7,1.8] \times$

$[0,0.001,0.005,0.01,0.05]$ (RIG 1). The upper integration boundary was set to the (maximum available) $r_{\max }=2.2$. The results reveal a pattern

Table 1. Dust layer 2-2.75 km (averaged).

\begin{tabular}{|c|c|c|c|c|}
\hline \multicolumn{5}{|c|}{ Optical properties } \\
\hline $\begin{array}{c}\alpha 355 \\
\left(\mathrm{Mm}^{-1}\right)\end{array}$ & $\begin{array}{c}\beta 355^{1 / / / F} \\
\left(\mathrm{Mm}^{-1} \mathrm{sr}^{-1}\right)\end{array}$ & $\begin{array}{c}\alpha 532 \\
\left(\mathrm{Mm}^{-1}\right)\end{array}$ & $\begin{array}{c}\beta 532^{\| / / /} \\
\left(\mathrm{Mm}^{-1} \mathrm{sr}^{-1}\right)\end{array}$ & $\begin{array}{c}\beta 1064^{\| / / /} \\
\left(\mathrm{Mm}^{-1} \mathrm{sr}^{-1}\right)\end{array}$ \\
\hline 98.50 & $1.69 / 0.41$ & 92.51 & $1.56 / 0.45$ & $1.17 / 0.27$ \\
\hline \multicolumn{5}{|c|}{ Intensive properties } \\
\hline $\begin{array}{c}\delta 355 / 532 / 1064 \\
(\%) \\
24 \pm 0.0 / 29 \pm 0.0 / \\
23 \pm 0.0\end{array}$ & $\begin{array}{c}\text { LR355 } \\
\text { (sr) } \\
47.71 \pm 5.2\end{array}$ & $\begin{array}{c}\text { LR532 } \\
\text { (sr) } \\
46.34 \pm 2.94\end{array}$ & $\begin{array}{c}\mathrm{AE}^{\alpha} \\
355 / 532 \\
0.16 \pm 0.09\end{array}$ & $\begin{array}{c}A E^{\beta} \\
355 / 1064 \\
0.48 \pm 0.02\end{array}$ \\
\hline
\end{tabular}


which allows to categorize them in three (second not shown here) altitude ranges, namely 1.5 $2.75 \mathrm{~km}, 2.75-3.25 \mathrm{~km}$ and $3.25-4 \mathrm{~km}$, only by observing the largest parameter variation, see Table 2. In this table, the variability (Var \%) refer to the 5 best solutions for a single dataset corresponding to a specific altitude range, and the mean variability pertains to more than one datasets are involved. The uncertainty (Unc \%) of the mean parameter value, found for every altitude range, is also given; here the input-datasets correspond to different altitude ranges.

Especially for the complex refractive index and the single scattering albedo retrieved by AERONET, the given values represent spectral mean values in the four almucantar wavelengths. Hence, Var (\%) corresponds to a mean spectral variability, and the given Unc (\%) corresponds to the uncertainty of the mean retrieved parameters (spectrally) between the consecutive measurements. We can see clearly from Table 2 that our algorithm demonstrates very

Table 2. Retrieved microphysical parameters.

\begin{tabular}{|c|c|c|c|c|c|c|}
\hline \multicolumn{7}{|c|}{ RIG 1, RRI=1.4 (Var, Unc: 0.0\%, IRI=0.05 (Var, Unc: 0.0\%) } \\
\hline \multicolumn{2}{|c|}{$2.0-2.75 \mathrm{~km}$} & \multicolumn{5}{|c|}{ / SSA532=0.685 (Var: $1.40 \%)$} \\
\hline $\begin{array}{c}\text { Para- } \\
\text { meter } \\
\text { Unit }\end{array}$ & $\begin{array}{c}a_{\mathrm{t}} \\
\mu \mathrm{m}^{2} \mathrm{~cm}^{-3}\end{array}$ & $\begin{array}{c}v_{\mathrm{t}} \\
\mu \mathrm{m}^{3} \mathrm{~cm}^{-3}\end{array}$ & $\begin{array}{c}r_{\text {eff }} \\
\text { (total/fine } \\
/ \text { coarse } \\
\mu \mathrm{m}\end{array}$ & svcf & $a_{\text {eff }}$ & $a_{\text {var }}$ \\
\hline $\begin{array}{l}\text { Ave- } \\
\text { rage }\end{array}$ & 160.68 & 36.44 & $\begin{array}{c}0.68 / 0.29 \\
/ 1.45\end{array}$ & 0.31 & 1.10 & 0.046 \\
\hline $\begin{array}{c}\text { Varia- } \\
\text { bility } \\
\% \\
\end{array}$ & 3.71 & 5.36 & $\begin{array}{c}4.62 / 3.09 \\
/ 1.54 \\
\end{array}$ & 4.01 & 0.38 & 3.72 \\
\hline \multicolumn{7}{|c|}{$1.5-2.75 \mathrm{~km}$, step: $250 \mathrm{~m} \quad / \mathrm{SSA} 332=0.684$ (Var: $3.20 \%$, Unc: $1.11 \%)$} \\
\hline $\begin{array}{l}\begin{array}{l}\text { Ave- } \\
\text { rage }\end{array} \\
\end{array}$ & 163.07 & 38.63 & $\begin{array}{c}0.71 / 0.35 \\
/ 1.45\end{array}$ & 0.31 & 1.10 & 0.046 \\
\hline $\begin{array}{c}\text { Varia- } \\
\text { bility } \\
\%\end{array}$ & 2.88 & 7.00 & $\begin{array}{c}5.54 / 4.67 \\
/ 1.68\end{array}$ & 3.79 & 0.53 & 2.87 \\
\hline $\begin{array}{c}\text { Uncer- } \\
\text { tainty } \\
\%\end{array}$ & 2.84 & 6.75 & $\begin{array}{c}5.00 / 27.17 \\
/ 0.58\end{array}$ & 1.33 & 0.21 & 1.55 \\
\hline \multicolumn{7}{|c|}{$3.25-4.0 \mathrm{~km}$, step: $250 \mathrm{~m} \quad /$ SSA532 $=0.677$ (Var: $2.44 \%$, Unc: $0.81 \%$ ) } \\
\hline $\begin{array}{l}\text { Ave- } \\
\text { rage }\end{array}$ & 65.24 & 16.28 & $\begin{array}{c}0.753 / 0.398 \\
/ 1.46\end{array}$ & 0.32 & 1.10 & 0.046 \\
\hline $\begin{array}{c}\text { Varia- } \\
\text { bility } \\
\%\end{array}$ & 2.65 & 8.04 & $\begin{array}{c}6.71 / 7.26 \\
/ 1.36\end{array}$ & 3.75 & 0.54 & 2.89 \\
\hline $\begin{array}{c}\text { Uncer- } \\
\text { tainty } \\
\%\end{array}$ & 10.05 & 3.22 & $\begin{array}{c}10.12 / 32.83 \\
/ 0.37\end{array}$ & 3.89 & 0.57 & 2.42 \\
\hline
\end{tabular}

good stability. There is virtually no difference in the microphysical retrieval between considering the whole range $2-2.75 \mathrm{~km}$ and splitting the even larger range $1.5-2.75 \mathrm{~km}$ to 5 smaller ranges of $250 \mathrm{~m}$. The uncertainty of all parameters is very low and thus we could consider any of these height ranges to arrive to similar results. We should note that this efficiency could be largely the result of good quality data and the fact that we use the maximum number of depolarization data available at the present time.

Our algorithm predicts large particles, as expected for an intense dust event, with a total effective radius of $0.71 \mu \mathrm{m}(1.5-2.75 \mathrm{~km})$ which is constituted by fully separated modes (Fig. 3), i.e. with $r_{\text {eff }}$ fine $0.35 \mu \mathrm{m}$ and $r_{\text {eff }}$ coarse $1.45 \mu \mathrm{m}$. Focusing on higher altitudes, i.e. $(3.25-4 \mathrm{~km})$, where $\mathrm{AE}^{\alpha} 355 / 532$ is close to smaller values we also see in $1.5-2.75 \mathrm{~km}$ (or even tinier), the effective radii (total, fine or coarse) follows the expected upscaling relatively to values for 2.75 $3.25 \mathrm{~km}$ (not shown). Another notable characteristic is that the effective radius in (3.25 $4 \mathrm{~km})$ is still well-retrieved despite the dramatic attenuation of signal in these heights. The attenuation is already visible above $2.75 \mathrm{~km}$, see Fig. 2, and in terms of the microphysical retrieval it is translated into a diminished surface-area and total volume concentration see Table 2 , as it was intuitively expected.

The effective shape behavior is attributed to prolate particle ensembles with $a_{\text {eff }}=1.10$ and oblate particle ensembles with $a_{\text {eff }}=0.046$. The sphericity rate $0.20 \%$ (Var: $17.18 \%$ ) predicted by AERONET (Table 3) shows no involvement of spherical and (to some extent) fine particles. By comparison, the spherical volume concentration fraction (lidar) svcf, found 0.31 (Var: 3.79\%, Unc: 1.33 ) in $1.5-2.75 \mathrm{~km}$, shows that there could be spherical-particle contributions. We note that AERONET's sphericity parameter refers to the percentage of the spherical- vs the non-spherical component (assumed by AERONET's forward model), and thus there is only a rough correspondence of this quantity with svcf.

We get a more detailed visual of our retrieval by looking at the (mean) retrieved shape-size distribution for the altitude range $1.5-2.75 \mathrm{~km}$ in Fig. 3. There we see two very well separated modes, namely a narrower fine-to-medium-coarse mode and a much broader coarse mode, with volume concentration peaks about 58 and 48 $\mu \mathrm{m}^{3} \mathrm{~cm}^{-3}$ at about 0.43 and $1.45 \mu \mathrm{m}$ respectively. There are contributions of all kinds of spheroidal 
particle geometries (also spherical), and for higher aspect ratios $(\mathrm{a} \geq 1.20)$ the fine-coarse peak difference fades, so that both modes maxima equalize at about $30 \mathrm{\mu m}^{3} \mathrm{~cm}^{-3}$. Fig. 4 shows also the reduced volume concentration size distribution (left) and the volume concentration size distribution retrieved by AERONET (right). The latter shows merely a very prominent coarse mode predicting very large particles. The complete absence of a fine mode is often a mathematical artifact when one of the expected modes is much more dominant than the other, and the smoothing process suppresses or eliminates the smaller one.

Although the lidar-based (reduced) VCSD is not directly comparable quantitatively to the latter, as mentioned earlier, we can see that the volume concentration is of the same order in both subfigures by specifying the altitude. In this sense and by considering the thickness of the whole dust layer about $3.5 \mathrm{~km}$, the estimated maximum lidarretrieved concentration is about $0.14 \mu \mathrm{m}^{3} \mu \mathrm{m}^{-2}$ which is comparable with AERONET's maximum of about $0.24 \mu^{3} \mu^{-2}$. Since the volume concentration is obviously not constant along the aerosol layer and also the sampled volume is different in the two cases, this calculation has no practical purpose other than the order comparison.

The refractive index is found $1.4+0.05 i$ through all layers $(1.5-4)$ and with $0 \%$ uncertainties (Var, Unc), and SSA532 $=0.684$

Table 3. AERONET sun-photometer-based inversion results.

\begin{tabular}{|c|c|c|c|c|c|c|}
\hline $\begin{array}{l}\text { Para- } \\
\text { meter } \\
\text { Unit } \\
\end{array}$ & $\begin{array}{c}u_{\mathrm{t}} \\
\mu \mathrm{m}^{3} \mu \mathrm{m}^{-2}\end{array}$ & $\begin{array}{c}r_{\text {eff }} \\
\text { (total/fine } \\
\text { /coarse) } \\
\mu \mathrm{m} \\
\end{array}$ & $\begin{array}{c}\text { speri- } \\
\text { city } \\
\% \\
\end{array}$ & RRI & IRI & SSA \\
\hline Average & 0.40 & $\begin{array}{c}1.30 / 0.16 \\
/ 1.87\end{array}$ & 0.20 & 1.52 & 0.0017 & 0.963 \\
\hline $\begin{array}{c}\text { Varia- } \\
\text { bility \% }\end{array}$ & 6.21 & $\begin{array}{c}7.25 / 6.35 \\
/ 7.27\end{array}$ & 17.18 & 1.02 & 21.13 & 0.77 \\
\hline $\begin{array}{c}\text { Uncer- } \\
\text { tainty \% }\end{array}$ & - & - & - & 1.54 & 64.24 & 2.27 \\
\hline
\end{tabular}

(Var: $3.20 \%$, Unc: $1.11 \%$ ) which points to highly absorbing particles. This might not be as common for such an event but it is also not incredible. Experimental findings have shown that such a high absorption can mainly be found near the sources of dust events. For instance, a soil sample from Burkina Faso (rich in hematite and kaolinite) was found in [8] using also a spheroid-particle-based inversion scheme to have IRI $=0.0495 \pm 0.0206$ at $305 \mathrm{~nm}$. Moreover, [9] found that the IRI increases a lot (up to 0.03 ) with decreasing particle size $(<0.5 \mu \mathrm{m})$, again due to the predominant hematite / soot component in smaller particles. AERONET's retrieval suggests, on the contrary, a refractive index with RRI $=1.52$ (Var: $1.02 \%$, Unc: $1.54 \%$ ) and IRI $=0.0017$ (Var: $21.13 \%$, Unc: $64.24 \%$ ), and SSA $=0.963$ (Var: $0.77 \%$, Unc: $2.27 \%$ ), i.e. weakly absorbing particles. However, this IRI is even lower than the usual values considered for Saharan dust particles, see e.g. [10]. The latter study also finds a dramatic increase in IRI (up to five times higher at $637 \mathrm{~nm}$ ) when the dust concentration is lower so that a soottype absorber prevails.

\section{CONCLUSIONS}

The results generally conform to usual dust characteristics, i.e. relatively large size $\left(r_{\text {eff }}\right)$ and reduced sphericity (svcf) and they further show a volume concentration order in accordance to the one of AERONET independent retrieval, although the high absorption found requires further investigation. Finally, multiple inversions in sublayers of $250 \mathrm{~m}$ demonstrated the stability of the algorithm along with its sensitivity to particle size variation.

\section{ACKNOWLEDGEMENTS}

The work has been supported partially by the EU under grant agreement No.289923 - ITaRS and EU's Horizon 2020 under No.654109 (ACTRIS2).

\section{REFERENCES}

[1] M. Haarig, et al. Atmospheric Chemistry and Physics, 17(17): 10767-10794, (2017).

[2] M. Haarig, et al. Atmospheric Chemistry and Physics, 17(23): 14199-14217, (2017).

[3] R.-E. Mamouri, and A. Ansmann, AMT, 10(10): 3403-3427, (2017).

[4] T. Rother and M. Kahnert, Springer, NY,(2014).

[5] S. Samaras, PhD thesis, Potsdam University, (2017).

[6] C. Böckmann, and A. Kirsche, Computer Physics Communications, 174(8): 607-615, (2006).

[7] C. Böckmann, and L. Osterloh, Inverse Problems in Science and Engineering, 22(1): 150-165, (2014).

[8] R. Wagner, et al. Atmospheric Chemistry and Physics, 12(5): 2491-2512, (2012)

[9] K. Kandler, et al. Atmospheric Environment, 41(37): 8058 - 8074, (2007).

[10] A. Schladitz, et al. Tellus B, 61(1): 64-78, (2009). 